\title{
FRACTURE PROPERTIES OF GEOPOLYMER CONCRETE CURED IN AMBIENT TEMPERATURE
}

\author{
PRADIP NATH ${ }^{1}$ and PRABIR KUMAR SARKER ${ }^{2}$ \\ ${ }^{1}$ PhD student, Department of Civil Engineering, Curtin University, Perth, Australia. \\ ${ }^{2}$ Senior Lecturer, Department of Civil Engineering, Curtin University, Perth, Australia.
}

\begin{abstract}
Geopolymer concrete (GPC) is a promising alternative of ordinary Portland cement (OPC) concrete. Recent studies indicate potential benefit of heat cured geopolymer concrete in structural applications. This study aimed at the fracture behavior of fly ash based geopolymer concrete cured in ambient temperature. Geopolymer concretes were prepared with mainly fly ash as the binder which was activated by a mixture of sodium hydroxide and sodium silicate solutions. Ground granulated blast furnace slag (GGBFS) was added up to $20 \%$ of total binder and amount of alkaline solution was varied to determine the effect on concretes subjected to ambient curing. Notched beam specimens were cast and cured in air at $16-22{ }^{\circ} \mathrm{C}$ and $70 \pm 10 \%$ relative humidity. Three-point bending test was conducted using a closed-loop universal testing machine. The fracture energy values were calculated from the load-deflection curves of the test specimens by using the work of fracture method. The critical stress intensity factors of the specimens were also calculated. The load-deflection curves and the fracture behavior of different geopolymer concretes were compared. Generally, the fracture energy varied with the strength of the concrete. The fracture energy of concrete having slag in addition to fly ash was higher than that having only fly ash. Geopolymer concretes achieved higher fracture energy values as compared to OPC concrete of similar compressive strength.
\end{abstract}

Keywords: Fly ash, fracture energy, geopolymer concrete, slag.

\section{Introduction}

Geopolymer is a synthetic inorganic polymer. It is synthesized by activating various alumino-silicate materials with alkaline solutions (Davidovits 2008). Geopolymer concrete (GPC) is a potential material as an alternative of ordinary Portland cement (OPC) concrete. GPC can play a significant role in green concrete technology by eliminating cement and utilizing various by-product materials such as fly ash and blast furnace slag. Studies conducted over the last decades indicated potential benefits of fly ash based geopolymer over OPC concrete (Hardjito 2005, Rangan 2008). Low-calcium fly ashbased geopolymer concrete has been reported to have excellent mechanical and durability properties (Wallah and Rangan, 2006). However, most of the GPC tested so far was either heat cured or steam cured at higher temperature than ambient. While such GPC can be precast easily, it is not always practicable in cast-in-situ applications due to delayed setting and slow strength development in ambient condition. Hence it is necessary to develop GPC suitable for ambient curing condition and to investigate its structural properties.

Fracture characteristics are important part of concrete design against brittle failure. It can be governed by the mixture proportions, curing process and the maturity of concrete. As a new material, reports on fracture properties of GPC are very scarce. Recently Sarker et al. (2012 online) reported properties of heat cured fly ash based GPC and compared with OPC concrete. The heat cured GPC showed similar or higher fracture energy as OPC concrete of similar strength. Critical stress intensity factor of GPC is also found to be higher than OPC concrete. Bonding performance of heat cured GPC is generally better than OPC concrete (Sofi et al. 2007; 
Fracture properties of geopolymer concrete cured in ambient temperature Nath, P. and Sarker P. K.

Sarker 2011). Structural behaviors of geopolymer concrete beams were studied in short scale which indicated superior performance of heat cured GPC than normal OPC concrete (Sumajouw et al. 2005, Chang et al. 2007). However, reports on the properties of ambient cured GPC are scarce in literature.

Fly ash based geopolymers produced in ambient temperature achieve lower strength in the early days as compared to heat cured samples (Vijai et al. 2010). Geopolymer concrete produced without using elevated heat for curing will widen its application to the areas beyond precast members. Hence this study aimed to study the fracture properties of fly ash based geopolymer concrete designed for ambient curing condition. Mixtures developed in a continued project (Nath and Sarker 2012) were tested for this study.

Table1: Chemical composition of fly ash and GGBFS.

\begin{tabular}{lcc}
\hline & Flyash (\%) & GGBFS (\%) \\
\hline $\mathrm{SiO}_{2}$ & 53.71 & 29.96 \\
$\mathrm{Al}_{2} \mathrm{O}_{3}$ & 27.20 & 12.25 \\
$\mathrm{Fe}_{2} \mathrm{O}_{3}$ & 11.17 & 0.52 \\
$\mathrm{CaO}$ & 1.90 & 45.45 \\
$\mathrm{Na} \mathrm{N}_{2} \mathrm{O}$ & 0.36 & 0.31 \\
$\mathrm{~K}_{2} \mathrm{O}$ & 0.54 & 0.38 \\
$\mathrm{SO}_{3}$ & 0.30 & 3.62 \\
$\mathrm{P}_{2} \mathrm{O}_{5}$ & 0.71 & 0.04 \\
$\mathrm{TiO}_{2}$ & 1.62 & 0.46 \\
Loss on & 0.68 & 2.39 \\
ignition & &
\end{tabular}

\section{Experimental program}

\subsection{Materials}

Geopolymer concretes were designed with Class F fly ash (ASTM C 618) as primary aluminosilicate source. Commercially available GGBFS was added up to $10 \%$ of total binder to enhance the properties of concrete. The fly ash was obtained from a Western Australian power plant. The chemical compositions of fly ash and GGBFS are shown in Table 1. A mixture of sodium hydroxide ( $\mathrm{SH}$ ) and sodium silicate (SS) solutions was used as alkaline activator for the alumino-silicate binders. The sodium hydroxide solution concentration was 14 Molar. Sodium silicate solution with $\mathrm{SiO}_{2}$ to $\mathrm{Na}_{2} \mathrm{O}$ ratio by mass of $2.61\left(\mathrm{SiO}_{2}=30.0 \%\right.$, $\mathrm{Na}_{2} \mathrm{O}=11.5 \%$ and water $=58.5 \%$ ) was used. Crushed granite with nominal maximum size of 7,10 and $20 \mathrm{~mm}$ were used as coarse aggregates. Natural sand with a nominal maximum size of $1.18 \mathrm{~mm}$ was used as fine aggregate. Potable tap water was used and a naphthalene-based superplasticiser was used to improve workability. For OPC concrete, a general purpose Portland cement was used.

Table2: Details of geopolymer and OPC concrete mixture proportions $\left(\mathrm{kg} / \mathrm{m}^{3}\right)$

\begin{tabular}{lccccc}
\hline Mix no & GPC1 & GPC2 & GPC3 & GPC4 & OPC \\
\hline & A40 & A40 & A35 & A35 & - \\
& S00 & S10 & S00 & S20 & \\
Label & R2.5 & R2.5 & R2.5 & R2.5 & \\
\hline CA $^{\text {a }}$ & 1209 & 1209 & 1218 & 1218 & 793 \\
Sand & 651 & 651 & 656 & 656 & 912 \\
Cement & - & - & - & - & 388 \\
Fly ash & 400 & 360 & 400 & 360 & \\
GGBFS & 0 & 40 & 0 & 40 & - \\
SS $^{b}$ & 114.3 & 114.3 & 100 & 100 & - \\
SH $^{\text {c }}$ & 45.7 & 45.7 & 40 & 40 & - \\
Water $^{\text {Sad }}$ & 0 & 0 & 0 & 6 & 213 \\
SP $^{\mathrm{d}}$ & 0 & 0 & 6 & 6 & 0 \\
${ }^{a}$ Coarse aggregate; & ${ }^{b}$ Sodium silicate solution; \\
${ }^{\mathrm{c}}$ Sodium hydroxide solution; & ${ }^{d}$ Superplasticiser
\end{tabular}

\subsection{Preparation of samples}

\subsubsection{Mixture proportions}

Four geopolymer concrete (GPC) and one OPC concrete mixture were designed. The mixture proportions of all mixtures are shown in Table 2. Mixture variables include the percentage of slag and the amount of alkaline activator solution. Mixture GPC1 and GPC3 were designed with only fly ash as the binder, whereas mixture GPC2 and GPC4 were designed with $10 \%$ slag and $90 \%$ fly ash as binder. The activator solution was added in a ratio of $2.5(\mathrm{SS} / \mathrm{SH})$ and constituted as $35 \%$ (GPC3 and GPC4) and 40\% (GPC1 and 
GPC2) of the total binder. Extra water and superplasticiser was added in the mixtures having $35 \%$ activator solution to increase workability. The geopolymer mixtures were designated with their variable constituents in the mix. For example, A40 S10 R2.5 represents a geopolymer mixture having alkaline activator solution (A) as $40 \%$ of total binder, slag (S) as $10 \%$ of total binder and the ratio of sodium silicate and sodium hydroxide solution $(\mathrm{R})$ as 2.5 .

OPC concrete was designed in accordance with the ACI guideline (ACI committee 211 1991) to achieve 28-day compressive strength of about $40 \mathrm{MPa}$ to compare with similar GPC mixtures of similar strength.

\subsubsection{Casting and curing of specimens}

Notched beam specimens were prepared for fracture tests. The specimen was $600 \mathrm{~mm}$ long with $100 \times 100 \mathrm{~mm}$ cross section and a 25 $\mathrm{mm}$ deep notch at the mid-section. The mold was designed to facilitate carving the notch while casting the specimen. Standard cylinder specimens of $100 \mathrm{~mm} \times 200 \mathrm{~mm}$ size were cast for compressive strength tests. The molds were filled in two layers and compacted using a vibrating table. The specimens were demolded after one day of casting and left in the ambient curing condition $\left(16-22^{\circ} \mathrm{C}\right.$ and $70 \pm$ $10 \%$ relative humidity) until tested. The samples of GPC1 and GPC3 were de-molded after three days, because of long setting time of these mixtures observed in the previous studies (Nath and Sarker 2012).

\subsection{Testing and evaluation}

At 28 days, the fracture test was conducted with the specimens loaded in three-point bending. The beam was simply supported over a span of $500 \mathrm{~mm}$ on the notched face and a single point load was applied at the centre of the beam (Fig. 1). The test was conducted using a closed-loop universal testing machine (Instron Servo Control machine). The specimen was loaded to induce a vertical midsection deflection at a rate of $0.5 \mathrm{~mm} / \mathrm{min}$. This loading rate was selected after several trial tests to ensure the maximum load is reached within 30-60 seconds as recommended in RILEM guidelines (RILEM TC 50 - FMC 1985). Data of load and vertical deflection was recorded automatically at rate of 100 readings per second.

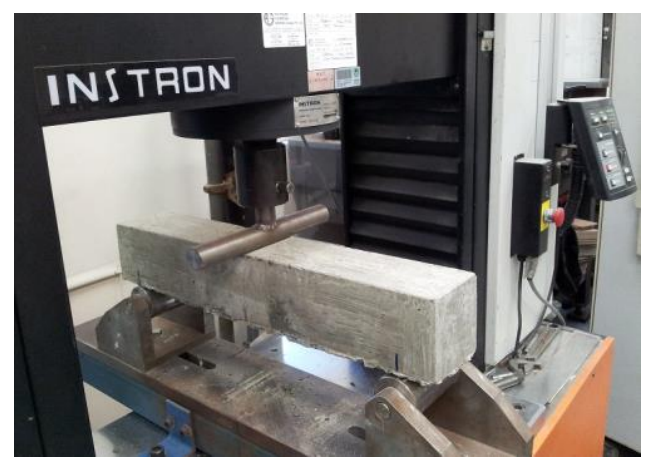

Figure 1. Three-point bending test set up.

The load-deflection graph was plotted with the recorded data. The load-deflection curve was corrected to straighten initial part of the curve by eliminating fluctuating data occurred due to low loading and contact surface adjustments at the beginning of the test. The fracture energy $\left(G_{F}\right)$ was calculated by work of fracture method (Eq. 1) (RILEM TC 50 - FMC 1985).

$$
G_{F}=\left(W_{o}+m g \delta_{o}\right) / A_{\text {lig }}
$$

Where, $W_{o}=$ area under the load-deflection curve $(\mathrm{N}-\mathrm{m}), m=$ weight of the beam between the support $(\mathrm{kg}), g=$ acceleration due to gravity $\left(9.81 \mathrm{~m} / \mathrm{s}^{2}\right), \delta_{o}=$ the deflection at the final failure of the beam (m) and $A_{\text {lig }}=$ area of the ligament $\left(\mathrm{m}^{2}\right)$.

The critical stress intensity factor $\left(K_{I C}\right)$ was calculated using Eq. 2 (Peterson 1980), which indicates the intensity of stress at the tip of crack as it initiates. It is also known as fracture toughness and relates to the peak load and the geometric dimensions of the beam. 
Fracture properties of geopolymer concrete cured in ambient temperature Nath, P. and Sarker P. K.

$$
\begin{aligned}
K_{I C}= & \left(3 P l / 2 b d^{2}\right) a^{0.5}\left(1.93-3.07 A+14.53 A^{2}-\right. \\
& \left.25.311 A^{3}+25.38 A^{4}\right)
\end{aligned}
$$

Where, $P=$ the peak load, $l=$ the span of beam, $b=$ the width of beam, $d=$ the depth of beam, $a=$ the depth of the notch and $A=a / d$.

\section{Results and discussions}

\subsection{Compressive strength}

The geopolymer concrete mixtures of this study were cured in ambient condition. Strength and fracture test were done at 28 days. Compressive strength varied in the range of 25 to $38 \mathrm{MPa}$ (Table 3). Mixtures having slag and fly ash blend as binder generally achieved higher strength than mixtures having only fly ash. The increase of strength was significant when no extra water was added (GPC2). When additional water was included to facilitate workability (GPC4), it reduced the concentration of alkaline activator solution which eventually decreased strength. However, inclusion of slag in GPC4 helped achieve strength similar to GPC3 which is having only fly ash as binder with no extra water. Higher strength was obtained when alkaline activator solution was decreased from $40 \%$ to $35 \%$ with no added water. The results resemble the observation reported in previous studies (Nath and Sarker 2012).

The OPC mixture that achieved $41 \mathrm{MPa}$ of compressive strength will be compared with the geopolymer concrete GPC2, of similar compressive strength.

Table 3. Test result summary.

\begin{tabular}{llccc}
\hline $\begin{array}{l}\text { Sample } \\
\text { ID. }\end{array}$ & $\begin{array}{l}\text { 28-day } \\
\text { strength } \\
(\mathrm{MPa})\end{array}$ & $\begin{array}{l}\text { Mean } \\
G_{F} \\
(\mathrm{~N} / \mathrm{m})\end{array}$ & $\begin{array}{l}\text { Mean } \\
\text { Peak } \\
\text { load } \\
(\mathrm{kN})\end{array}$ & $\begin{array}{l}\text { Mean } \\
K_{I C} \\
(\mathrm{MPa}- \\
\left.\mathrm{mm}^{1 / 2}\right)\end{array}$ \\
\hline GPC1 & 25.6 & 156.3 & 2.74 & 15.69 \\
GPC2 & 38.3 & 221.6 & 3.78 & 23.08 \\
GPC3 & 32.5 & 150.0 & 4.50 & 26.61 \\
GPC4 & 33.3 & 197.0 & 3.31 & 20.33 \\
OPC & 41.6 & 177.1 & 3.48 & 21.83 \\
\hline
\end{tabular}

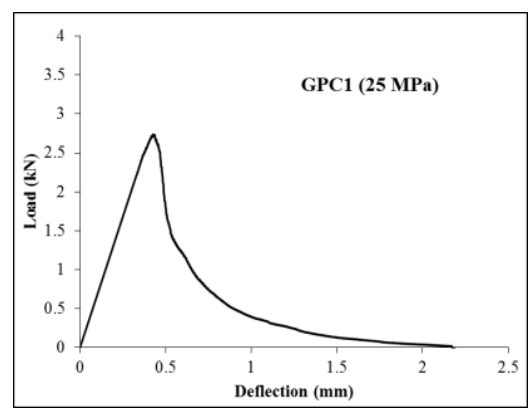

(a)

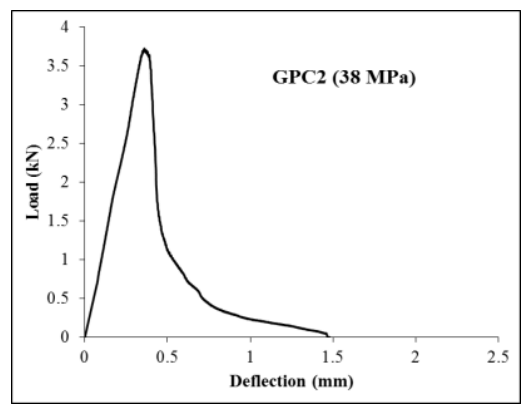

(b)

Figure 2. Typical load-deflection patterns of (a) GPC1 and (b) GPC2.

\subsection{Load-deflection behavior}

Three-point bending test was conducted on three specimens of each mixture and mean values of the parameters are presented in Table 3. Fig. 2 shows the typical loaddeflection patterns of two mixtures, one having no slag (GPC1) and another having $20 \%$ slag in the mixture (GPC2). The initial part of the curves were corrected to remove any non-linearity occurred from initial adjustment of the contact surfaces between supports and the concrete. As usual, the curve showed a linear upward slope until the load reached cracking limit. The slope was steeper for the higher strength specimens. Generally the slope of post-peak part of the curve decreased with the increase of the compressive strength. In other words concrete brittleness increased with the increase of compressive strength. 
Comparing the OPC concrete with a geopolymer mixture of similar strength (GPC2) it can be noticed that, GPC2 achieved slightly higher average peak load than the OPC mixture (Table 3). Typical curves of GPC2 and OPC mixtures were compared in Fig. 3. Both the mixture showed almost similar post-peak slopes, however OPC concrete allowed slightly more deflection than GPC2 before initiating crack.

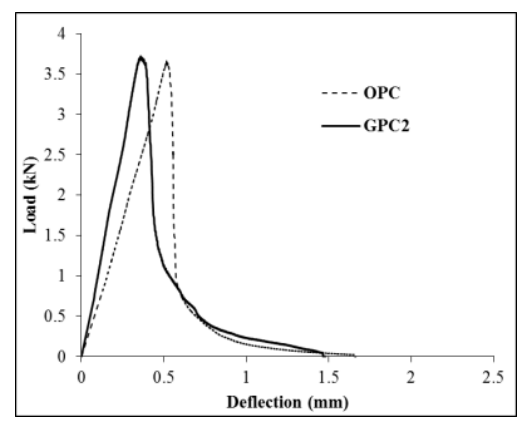

Figure 3. Comparison of typical load-deflection curves of GPC 2 and OPC concretes

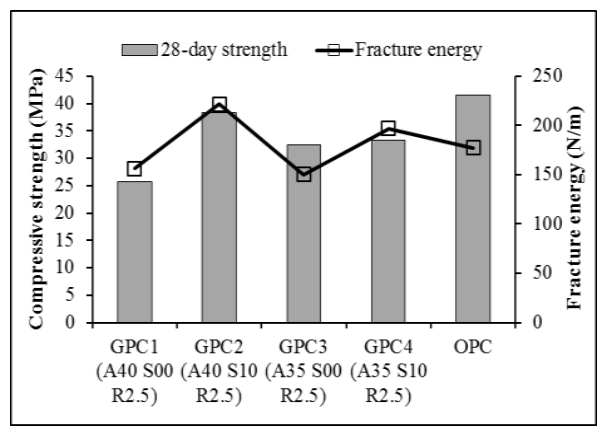

Figure 4. Results of fracture energy and strength.

\subsection{Fracture energy $\left(G_{F}\right)$ and fracture toughness $\left(K_{I C}\right)$}

The fracture energy and critical stress intensity factor for all the mixtures are shown in Table 3. The fracture energy followed a similar trend as compressive strength (Fig. 4). Fig. 5 shows the relationship of compressive strength with fracture energy $\left(G_{F}\right)$ and critical stress intensity factor $\left(K_{I C}\right)$. Both $G_{F}$ and $K_{I C}$ of geopolymer mixtures increased with the increase of compressive strength. The trend is similar to that reported for heat cured geopolymer mixtures (Sarker et al. 2012 online).

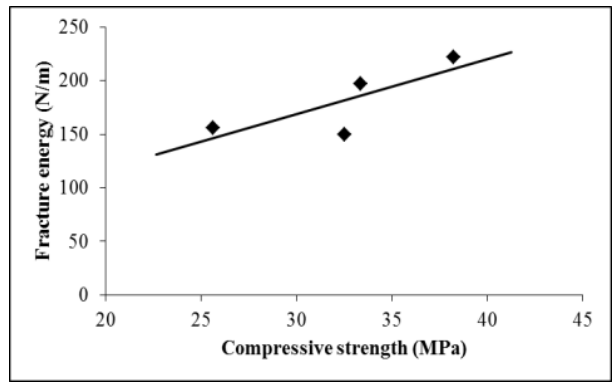

(a)

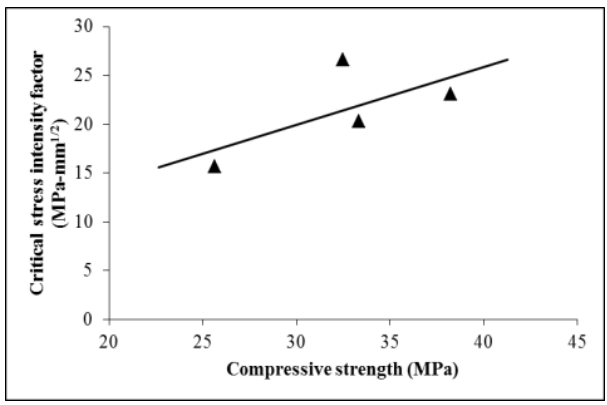

(b)

Figure 5. Relationship between compressive strength and (a) $G_{F}$ and (b) $K_{I C}$.

The mixture proportion influenced the fracture properties. Geoopolymer mixture GPC3, having 35\% activator solution, showed less fracture energy, but higher peak load and higher stress intensity factor than those of GPC1 which had $40 \%$ activator solution. It indicates that geopolymer concrete mixed with $35 \%$ activator solution increased load carrying capacity, but led to a more brittle failure as compared to the mixture with $40 \%$ activator solution. However, further study is required to validate the cause. When slag was included as $10 \%$ of fly ash, both fracture energy and fracture toughness increased (GPC2) as compared to mixture having only 
Fracture properties of geopolymer concrete cured in ambient temperature

Nath, P. and Sarker P. K.

fly ash (GPC1). In case of GPC4, addition of slag with extra water increased fracture energy and reduced the toughness. In general, fly ash based geopolymer concrete having slag as a partial additive improved the compressive strength as well as fracture energy.

When compared to OPC, the similar strength geopolymer mixture (GPC2) showed higher fracture energy and critical stress intensity factor.

\section{Conclusion}

This study investigated the fracture behavior of geopolymer concrete cured in ambient temperature. Fracture test was conducted on notched beam specimens loaded with three point bending. The following conclusions are drawn from the results:

- Geopolymer concrete designed with fly ash and slag achieved higher compressive strength than that designed with fly ash only. The fracture energy also increased with the inclusion of slag in the mixture.

- The fracture energy and critical stress intensity factor of ambient cured geopolymer concretes increased with the increase of compressive strength. Concretes also showed more brittle behavior with the increase of strength.

- Fracture behavior of a $40 \mathrm{MPa}$ grade GPC and OPC are mostly similar. Nevertheless, GPC showed slightly higher fracture energy and higher critical stress intensity factor than OPC concrete.

Finally, geopolymer concrete cured in ambient condition can achieve fracture properties comparable to normal OPC concrete. Mixture proportions of geopolymer concrete for curing in ambient temperature play a significant role for ensuring favorable compressive strength and fracture properties.

\section{Acknowledgments}

The authors gratefully acknowledge the supports from Coogee Chemicals, Western Australia.

\section{References}

ACI Committee 211, Standard Practice for Selecting Proportions for Normal Heavyweight, and Mass Concrete (ACI 211.1-91), American Concrete Institute.

ASTM C 618, Standard Specification for Coal Fly Ash and Raw or Calcined Natural Pozzolan for Use in Concrete. ASTM Int., West Conshohocken, PA, USA, 2008.

Davidovits, J., Geopolymer Chemistry and Application. 2nd edn, Institut Géopolymère, Saint-Quentin, France, 2008.

Hardjito, D., Studies of fly ash-based geopolymer concrete. $\mathrm{PhD}$ Thesis, Curtin university of Technology, Perth, Australia, 2005.

Nath, P., Sarker, P. K., Geopolymer Concrete For Ambient Curing Condition, in Australasian structural engineering conference, Perth, 11-13 July. 2012.

Peterson, P. E., Fracture Energy of Concrete: Method of Determination, Cem. Concr. Res., 10(1), 79-89, 1980.

RILEM TC 50-FMC, Determination of the fracture energy of mortar and concrete by means of three-point bend tests on notched beams, Mater Struct, 18, 285-290, 1985.

Rangan B. V. Fly Ash-Based Geopolymer Concrete, Research Report GC4, Curtin University of Technology Perth, Australia, 2008

Sarker, P. K., Bond Strength of Reinforcing Steel Embedded In Geopolymer Concrete, Mater Struct, 44, 1021-1030, 2011.

Sarker, P. K., Haque, R, Ramgolam, K. V.,Fracture Behaviour of Heat Cured Fly Ash Based Geopolymer Concrete, Materials \& Design, 44, 580-586, 2013 (2012 online).

Sofi, M., van Deventer, J. S. J., Mendis, P. A., Lukey, G. C., Bond Performance Of Reinforcing Bars in Inorganic Polymer Concretes, J Mater Sci, 42, 3107-3116, 2007.

Vijai, K., Kumutha, R. and Vishnuram, B. G., Effect of Types of Curing on Strength of Geopolymer Concrete. Inter. J. Physical Sci., 5(9), 1419-1423, 2010.

Wallah, S. E. and Rangan, B. V., Low-calcium fly ash-based geopolymer concrete: long-term properties. Research Report GC 2, Faculty of Engineering, Curtin University of Technology, Perth, Australia, 2006. 